\title{
Inclusión del alumnado con discapacidad en los estudios superiores. Ideas y actitudes del colectivo estudiantil
}

\author{
Inclusion of students with disabilities in higher education. \\ Ideas and attitudes of the students
}

\section{Resumen}

La inclusión socioeducativa del alumnado con discapacidad en los estudios superiores ha comenzado a ser objeto de investigación en los últimos años. En este trabajo analizamos esta situación de inclusión en la Universidad Pública de Navarra (UPNa) desde la perspectiva de quienes cursan titulaciones de las ramas de Ciencias Humanas y Sociales, Económicas y Jurídicas, por cuanto en ellas se concentra la mayoría de estudiantes con discapacidad. En colaboración con la Sección de Acción Social y del profesorado se ha obtenido información por medio de una encuesta sobre qué ideas y actitudes tiene el alumnado de la UPNa hacia sus iguales con discapacidad.

\section{Palabras clave}

Estudios superiores, discapacidad, inclusión socioeducativa, ideas, actitudes.

\begin{abstract}
The socio-educational inclusion of students with disabilities in higher education has begun to be a subject of research in recent years. In this work we analyze the situation of inclusion in the Public University of Navarra (UPNa) from the perspective of those who study degrees in Humanities and Social Sciences, Economics and Law, since the majority of students with disabilities usually study these university degrees. In collaboration with the Social Action Section and the teaching staff, relevant information has been obtained through a survey about what ideas and attitudes the UPNa students have towards their peers with disabilities.
\end{abstract}

\section{Keywords}

Higher education, disability, socioeducational inclusion, ideas, attitudes.

\author{
Berta Alba Moneo Estany \\ <b.a.moneoestany@hotmail.com> \\ Universidad Pública de Navarra
}

\section{Sagrario Anaut Bravo}

<sanaut@unavarra.es>

Universidad Pública de Navarra
Para citar:

Moneo, B. A. y Anaut, S. (20I7):

"Inclusión del alumnado con discapacidad en los estudios superiores. Ideas y actitudes del colectivo estudiantil". Revista Española de Discapacidad, 5 (2): I29-I48.

Doi: <https://doi.org/IO. 5569/23405 I04.05.02.07>

Fecha de recepción: 27-03-20I7 Fecha de aceptación: I I-IO-20I7 


\section{Introducción}

Es posible hablar de avances importantes en materia de reconocimiento de derechos, de reducción de las situaciones de discriminación, de implicación de los responsables políticos en materia de desarrollo normativo y de prestaciones de diversa índole, así como de visibilización de las situaciones en las que se encuentran las personas con discapacidad y sus entornos sociofamiliares. Para llegar a este punto, uno de los pilares que más ha influido en la transformación de las ideas y actitudes de la sociedad hacia las personas con discapacidad y que más ha hecho por su inclusión social es el sistema educativo.

La literatura deja constancia de los pasos dados en la inclusión del alumnado con discapacidad en los niveles educativos no universitarios. Tales acciones han llegado con retraso al nivel universitario, como se afirma en trabajos como los de la Fundación ONCE (20I4). Por ello, resulta pertinente conocer el nivel de inclusión de este alumnado a través de las ideas y actitudes que manifiestan estudiantes universitarios hacia sus iguales con discapacidad. Se cuenta ya con algunos trabajos centrados en esta temática como los de la Universidad de Almería (Sánchez, 2009) y la Universidad de Burgos (Martínez, 20IO). Hasta la fecha no se dispone de suficientes investigaciones para disponer de un panorama general de las universidades españolas, más aún cuando estas son claves en la formación de futuros profesionales y en la transformación de la sociedad. Estas páginas quieren aportar un nuevo estudio a este respecto, centrándose en la Universidad Pública de Navarra (UPNa).

2. Discapacidad e inclusión social en la educación superior

En la última década, los estudios publicados sobre las situaciones de exclusión o de inclusión social de las personas con discapacidad en España, han estado marcados por dos acontecimientos de diversa naturaleza. Por un lado, los acuerdos alcanzados en la Convención de Naciones Unidas sobre los derechos de las personas con discapacidad $(2006)^{\text {r }}$. Por otro, una crisis multidimensional y global que ha obligado a poner el énfasis de las políticas sociales en las cuestiones económico-laborales. Sirvan de muestra los trabajos de Flores y Jenaro (2009), Colectivo IOÉ (2OI2), Huete (20I3), Anaut y Arza (2015) o Anaut et al. (2017).

En materia educativa, la Ley General de derechos de las personas con discapacidad y de su inclusión social ${ }^{2}$ reconoce que "las personas con discapacidad conforman un grupo vulnerable y numeroso" (Preámbulo), por lo que las administraciones públicas son las responsables de la protección ("especialmente intensa") de sus derechos, entre los que cita la educación (artículo 7). Este reconocimiento cuenta con una dilatada experiencia en la que se fueron dando pasos hacia modelos educativos más inclusivos en los niveles obligatorios, sobre todo desde I994, y hacia la incorporación de la inclusión como principio rector del sistema educativo en España. Si bien se ha avanzado en materia de educación inclusiva gracias a la implicación de responsables políticos, profesorado (Cobos y Moreno, 20I4; Garzón et al., 2016) y familias con estudiantes con discapacidad, todavía sigue siendo uno de sus retos (Abellán et al., 20Iо; Escudero, 2012), sobre todo en los niveles postobligatorios.

Siguen siendo visibles las reticencias sociales a la hora de incluir la diversidad en la construcción física, social y mental del entorno socioespacial, al igual que la falta de reconocimiento de derechos y deberes, y la discriminación (Denhart, 2008; Ferreira, 2008a, 2008b). Tales rigideces se mantienen, a pesar de los esfuerzos hechos desde la citada Convención para visibilizar y mejorar la situación real de

I. En adelante, la Convención.

2. Real Decreto Legislativo I/20I3, de 29 de noviembre, por el que se aprueba el Texto Refundido de la Ley General de derechos de las personas con discapacidad y de su inclusión social. 
las personas con discapacidad (De Lorenzo y Palacios, 20I6; Moriña, 20I7).

Cuando España ratifica la Convención, acepta no excluir a las personas con discapacidad del sistema educativo, entendiéndose como un derecho a garantizar y como un medio de conocimiento y sensibilización social por parte de la ciudadanía (Cabeza, 20I3; Moriña et al., 20I4; Sánchez y Solar, 20I6). Así se ha garantizado su acceso en todos los niveles educativos en igualdad de condiciones, procurando las medidas de apoyo necesarias en función de las necesidades individuales y fomentando con ello el desarrollo académico y social en favor de su inclusión (Comisión Europea, 20I0; Sánchez, 20I I; GarcíaSantesmases y Herrero, 20I 2; Moriña, 20I 5; Núñez, 20I7).

La apuesta por una educación inclusiva llega a la educación superior con retraso respecto a los niveles educativos obligatorios (Moriña, 20I7). Uno de los hitos en este nuevo contexto es la Ley Orgánica 4/2007 de Universidades (LOU). En ella se establecen los principios de igualdad de oportunidades y no discriminación como garantizados, la accesibilidad de las instalaciones y servicios para todas las personas, y se promueve la participación plena y efectiva de este colectivo. Pero el impulso real ha venido de la convergencia del Plan Bolonia o el Espacio Europeo de Educación Superior (Díez et al., 20II), momento en el que se asume el compromiso con la creación de entornos de formación accesibles a todas las personas a través de los apoyos proporcionados a y por las universidades (Rodríguez-Martín y ÁlvarezArregui, 2014).

Hasta la fecha, sin embargo, se dispone de suficientes evidencias que apuntan a la falta de inclusión de estudiantes universitarios con discapacidad, en particular en el ingreso y permanencia, a pesar de su creciente número ${ }^{3}$.

3. Muestra de ello: Moreno et al., 2006; Denhart, 2008; Martínez, 20Iо; Suriá et al., 20I I; Díez et al., 20I I; Guasch, 20I 2; Moriña et al., 20I4; Moriña, 20I 5; González y Roses, 2016; Fundación Universia, 2016.
Este hecho resulta significativo si se tiene en cuenta que un rasgo frecuente de las personas con discapacidad es su bajo nivel educativo y las dificultades para llegar a cursar estudios postobligatorios (Anaut et al., 20I0; Díez et al., 20I I; Martín-Padilla et al., 20I3).

De igual forma ha podido constatarse que no siempre se ha contado con la diversidad de necesidades de estos estudiantes con discapacidad a la hora de diseñar el currículo de una titulación, las condiciones de accesibilidad, los sistemas de apoyo, la metodología docente o la formación de profesionales (Palacios, 2008; Valcarce, 20I I; Cano, 20I 2; Moriña et al., 20I4). En este mismo sentido hay que entender la permanencia de barreras arquitectónicas, las rigideces curriculares y los prejuicios y estereotipos fijados en el imaginario de la población (Suriá et al., 20I I; Moriña, 20I 5), cuando se reclaman espacios basados en el principio de diseño universal para todas las personas y la puesta en marcha de servicios, programas y unidades de atención para estudiantes con discapacidad (Díez et al., 20I I; Powell, 20I3; Cobos y Moreno, 20I4; Moriña, 2017).

Tomando este contexto, la Fundación ONCE, primero a través del IMSERSO (García de Sola, 2006) y, a día de hoy, con el apoyo del Real Patronato sobre Discapacidad y la Conferencia de Rectores de las Universidades Españolas (CRUE), inicia una línea de trabajo que aspira a subsanar algunas deficiencias. El resultado es la publicación y puesta en marcha del proyecto Formación Curricular en Diseño para Todas las Personas (Fundación ONCE, 2OI4), herramienta de utilidad para la mayoría de las titulaciones universitarias. Los documentos resultantes pretenden garantizar a los estudiantes universitarios el aprendizaje de unas competencias transversales que necesitan para ejercer la profesión elegida y saber cómo debe construir su relación con las personas con discapacidad (Fundación ONCE, 20I4). Asimismo, se busca una mejora de la situación, favoreciendo su autonomía y libertad en un marco de igualdad de oportunidades. En definitiva, se quiere ayudar en la implementación 
de una formación transversal sobre discapacidad para lograr que las personas que se encuentran en esta situación sean parte activa de la sociedad en la que viven (Aragall, 2008), y para que quienes no teniendo discapacidad muestren una actitud inclusiva en esos mismos entornos.

Los efectos de cuanto se ha ido haciendo por la inclusión de las personas con discapacidad pueden valorarse a partir de las actitudes que se tienen hacia estas en los procesos de socialización de los contextos familiar, educativo, social y laboral. Las actitudes, por su propia naturaleza, revelan un compromiso que va más allá de las ideas (Sánchez, 2009; 20II), entendiéndose como la predisposición hacia la persona con discapacidad (Muñoz-Cantero et al., 2013). Como afirman Verdugo et al. (1994) y, posteriormente, Martínez (2010) y Salinas (20I4), los tres componentes que constituyen una actitud son: la idea (componente cognitivo), la emoción asociada a ella (componente afectivo) y la predisposición a la acción (componente conductual). Martínez (2010) y Suriá et al. (20I I), en esta línea, consideran que las actitudes son aprendidas, sobre todo desde la experiencia. En base a ello, se entiende que las actitudes sean constructos psicosociales sobre los que una formación transversal puede incidir positivamente.

En los niveles universitarios la detección de actitudes positivas hacia los estudiantes con discapacidad es uno de los pilares básicos para el desarrollo de un contexto que promueva su inclusión y participación en este ámbito y producir un cambio de mentalidad en toda la comunidad universitaria (Martínez y Bilbao, 20I I; Núñez, 20I7). A ello va a contribuir, de forma significativa, una situación de convivencia cotidiana de quienes tienen o no discapacidad, siendo directamente proporcional la relación entre la inclusión y el desarrollo de un mayor grado de sensibilización (Novo-Corti y Muñoz-Cantero, 20I2). En este sentido, una buena relación entre estudiantes con y sin discapacidad, además de sentimientos de apoyo, compañerismo y ayuda, favorece la inclusión educativa, la incorporación y adaptación al mundo universitario y es garantía de una mayor autoestima y un grado más alto de aceptación personal (Moreno et al., 2006; Martínez, 2010; Muñoz-Cantero et al., 2013; González y Roses, 20I6).

Como se ha expuesto, la promoción de actitudes positivas entre estudiantes con y sin discapacidad supone un avance en términos de inclusión entre iguales, al mismo tiempo que en la propia comunidad universitaria, para lo que es necesaria la implicación de todos sus componentes (De la Fuente, 20I4; Moriña, 20I 5; 20I7). Como reconocen Denhart (2008), Guasch (20I2), Martín-Padilla et al. (2013), Cobos y Moreno (2014) o Núñez (2017), entre otros, es preciso ampliar el trabajo de sensibilización, formación y praxis, para avanzar realmente hacia una inclusión social plena, evitando así la invisibilidad y el desconocimiento que se tiene de este colectivo. La Fundación ONCE ha declarado a este respecto que el alumnado universitario que hoy en día se está formando como profesional también necesita concienciación y sensibilización para hacer de su práctica profesional una oportunidad y no una barrera en el futuro (De la Fuente, 20I4). No cabe duda de que todavía es pronto para tener resultados de los pasos dados en el entorno universitario, pero sin ellos no parece posible construir una sociedad inclusiva, capaz de reconocer la diversidad como una aportación y no como un obstáculo.

\section{Método}

La metodología adoptada se ajusta al objetivo central de valorar la situación de inclusión del alumnado con discapacidad en la Universidad Pública de Navarra (UPNa). Se ha optado por un estudio cuantitativo a través de una encuesta a una muestra compuesta por estudiantes pertenecientes a las Facultades de Ciencias Humanas y Sociales, Ciencias Económicas y Ciencias Jurídicas de la UPNa. Las cinco titulaciones elegidas son de las más demandadas por estudiantes con discapacidad y son de las que forman profesionales de proximidad (Tabla 2). 
Se ha realizado un muestreo no probabilístico que ha dado un total de 139 cuestionarios cumplimentados correctamente. El 32,4\% de los mismos corresponden a hombres y el $67,6 \%$ a mujeres, perfil coincidente con el que presentan estas titulaciones en la UPNa ${ }^{4}$. Por grupos de edad, predomina el de 2 I a 25 años, siendo la media de 22 años (Tabla I).

Tabla 1. Representación del alumnado que compone la muestra por grupos de edad (años 2014 y 2015). Porcentajes

\begin{tabular}{|l|c|}
\hline Grupos de edad & Porcentajes \\
\hline$<20$ & 24,5 \\
\hline $21-25$ & 63,3 \\
\hline $26-30$ & 9,3 \\
\hline$>31$ & 2,9 \\
\hline Total & 100 \\
\hline
\end{tabular}

Fuente: elaboración propia.

La distribución porcentual de la muestra por titulaciones recoge la representación de la mayoría de los cursos académicos (Tabla 2), estando sobre-representado el Grado en Trabajo Social por el tamaño medio de los grupos, sobre todo en los primeros cursos. No obstante, la distribución por facultades está bastante equilibrada. Un $40 \%$ de la muestra corresponde a las facultades de Ciencias Jurídicas y Ciencias Económicas y Empresariales, y un $60 \%$ a la Facultad de Ciencias Humanas y Sociales.
4. Las Facultades de Ciencias Sociales y Humanas, Ciencias Jurídicas y Ciencias Económicas y Empresariales contaban con 3865 estudiantes universitarios matriculados en los años 2OI4 y 2015 , siendo 2535 mujeres y I 330 hombres (datos facilitados por la propia UPNa).

\begin{tabular}{|c|c|}
\hline Curso y Titulación & Porcentajes \\
\hline $2^{\circ}$ Trabajo Social & 43,2 \\
\hline $3^{\circ}$ Relaciones Laborales & 25,9 \\
\hline $4^{\circ}$ Derecho y ADE & 13,7 \\
\hline $1^{\circ}$ y $2^{\circ} \mathrm{MU}$ Intervención Social ${ }^{5}$ & 17,3 \\
\hline Total & 100 \\
\hline
\end{tabular}

Fuente: elaboración propia.

\subsection{Técnicas e instrumentos empleados}

La estrategia de recogida de información seleccionada ha sido la encuesta de muestreo (Corbetta, 2003). Para registrar la información se utiliza como instrumento un cuestionario extenso, subdividido en tres partes:

- $\quad{ }^{\mathrm{a}}$ Parte: datos sociodemográficos básicos relativos a cada persona encuestada (I I ítems utilizando tanto variables nominales como ordinales y de intervalo): sexo, edad, estudios concluidos, curso en el que se encuentra actualmente, si tienen o no algún tipo de discapacidad y, si la respuesta es positiva, de qué tipo, contacto o no con personas que forman parte de este colectivo y tipo de relación mantenida, relación con estas personas dentro del sistema educativo y si han obtenido formación en esta materia dentro de la UPNa (Anexo I).

- $\quad 2^{\text {a }}$ Parte: ideas y actitudes en el ámbito educativo de los estudiantes universitarios hacia sus iguales con discapacidad. Parte del cuestionario fue aplicado en la Universidad de Almería (Sánchez, 2009). Utiliza una escala tipo Likert, compuesta de 39 ítems, de las cuáles cuatro interrogan sobre la política de discapacidad propia de la UPNa. El objetivo de ello ha sido conocer si el

5. Máster Universitario en Intervención Social con Individuos, Familias y Grupos. 
alumnado encuestado tiene constancia de la existencia de una normativa concreta en esta materia y un plan de acogida propio de la Unidad de Acción Social ${ }^{6}$. Las opciones de respuesta posibles son cuatro: dos en negativo, "Totalmente en desacuerdo", "En desacuerdo"; y dos en positivo, "De acuerdo" y "Totalmente de acuerdo". Se incluyen preguntas abiertas, preguntas cerradas con opción a una respuesta afirmativa o negativa y preguntas categorizadas.

Tabla 3. Ideas y actitudes del alumnado
universitario hacia estudiantes con discapacidad
\begin{tabular}{|l|l|}
\hline & $N^{\circ}$ DE PREGUNTA \\
\hline \multirow{3}{*}{ Ideas } & $\begin{array}{l}12,14,17,18,20,23,25,26,27, \\
28,29,30,31,32,33,36,37,38, \\
39,40,41,42,43,44,45,48,49 .\end{array}$ \\
\hline Actitudes & $13,15,16,19,21,22,24$. \\
\hline $\begin{array}{l}\text { Propias de la } \\
\text { UPNa }\end{array}$ & $34,35,46,47$. \\
\hline Observaciones & 50 \\
\hline
\end{tabular}

*Los diferentes ítems aparecen en el apartado de resultados.

Fuente: elaboración propia a partir de Sánchez (2009).

En relación con esta parte del cuestionario, y con el objetivo de facilitar el análisis de los resultados, ha sido necesario reformular algunos ítems. Al igual que hicieron Sánchez (2009), y Salinas (20I4) en sus respectivos estudios, algunos ítems enunciados en sentido negativo han sido recodificados con el objetivo de darle un sentido positivo a todo el cuestionario. Para llevar a cabo un análisis similar al de la segunda parte, en la tercera parte ha sido necesario reformular una serie de ítems, ya que algunos estaban formulados de forma positiva cuando la mayoría de ellos

6. La Unidad de Acción Social es un "servicio universitario de atención, apoyo y asesoramiento a la comunidad universitaria y desde el que se promueven y organizan actuaciones solidarias y sociales en la Universidad y hacia la sociedad" (Universidad Pública de Navarra, 20I6). tenían una acepción negativa (Martínez, 20I0). De esta manera, se adquiere mayor homogeneidad en las preguntas y se evitan errores de interpretación.

- $\quad 3^{\mathrm{a}}$ parte: Escala de Actitudes hacia las Personas con Discapacidad (Verdugo et al., I994), actualizada y aplicada en la Universidad de Burgos (Martínez, 20I0). Se trata de una escala tipo Likert similar a la anterior, pero con seis alternativas de respuesta: tres en negativo ("Muy en desacuerdo", "Bastante en desacuerdo" y "Algo en desacuerdo") y tres en positivo ("Algo de acuerdo", "Bastante de acuerdo" y "Muy de acuerdo"). Esta escala, formada por 37 ítems, está dividida en base a cinco factores que evalúan las actitudes hacia personas con discapacidad en la sociedad general: valoración de capacidades y limitaciones, reconocimiento/negación de derechos, implicación personal, calificación genérica y asunción de roles (Anexo 2).

La estructura del citado cuestionario responde a los objetivos específicos en los que se desglosa el objetivo central de analizar la inclusión social de los estudiantes con discapacidad:

- Conocer las ideas y actitudes de los estudiantes universitarios encuestados hacia sus iguales con discapacidad.

- Conocer la percepción general tanto dentro (Sánchez, 2009) como fuera (Martínez, 20I0) de las aulas.

- Identificar las relaciones entre las variables sociodemográficas y las ideas y actitudes de los estudiantes universitarios hacia sus iguales con discapacidad.

\subsection{Procedimiento}

Se ha contado con la colaboración de docentes de las titulaciones y cursos preseleccionados, que han facilitado el acceso a grupos completos de estudiantes en lo que denomina Sánchez (2009) como espacios cautivos (aulas). Tras la codificación de los cuestionarios cumplimentados, se han explotado con el SPSS v. 23 . 
Se han obtenido tres tipos de resultados:

- Datos sociodemográficos del alumnado universitario de los años 2014 y 2015.

- Ideas y actitudes hacia el colectivo de personas con discapacidad.

- Relaciones significativas entre diversos pares y grupos de variables según las ideas y actitudes, atendiendo a cuatro variables independientes: sexo, edad, contacto con personas con discapacidad y niveles educativos en los que se ha compartido o se comparte aula con este colectivo. Para valorar la incidencia de dichas variables independientes se ha utilizado el estadístico T-Student (dos muestras independientes) y la prueba ANOVA (variables con más de dos categorías).

\section{Resultados}

El estudio de la inclusión del alumnado con discapacidad de la UPNa se ha realizado para dimensionar el nivel alcanzado en las titulaciones con mayor visibilización de estos estudiantes. Para ello, los resultados obtenidos han quedado estructurados en tres apartados que han de permitir concluir si esa inclusión ha alcanzado niveles óptimos o si, por el contrario, la UPNa ha de articular acciones que redunden en una mayor inclusión socioeducativa de sus estudiantes con discapacidad.

\subsection{Ideas y actitudes hacia los estudiantes con discapacidad}

Las Tablas 4 y 5 muestran como media de las ideas y actitudes de los estudiantes un 3, IO en una escala de I a 4, lo que supone una percepción positiva general hacia el alumnado con discapacidad. Por un lado, la Tabla 4 muestra los resultados del factor teórico Ideas, con una media de 3, I I y una dispersión de 0,7 I. Las medias más bajas en cuanto a dicho factor se corresponden con aquellas preguntas que plantean la posibilidad de dar un trato diferenciado a quienes tienen discapacidad (números 25, 28, 33, 36 y 37), si bien se alcanza una media del 3,78 cuando se trata de facilitar el acceso (números I 2 y 42). Es decir, se apuesta por potenciar el acceso de los estudiantes con discapacidad, pero después no hay unanimidad de opiniones en el hecho de recibir o no un trato diferenciado (no hay que señalar/dar protagonismo: números 25 y 28). La dispersión de opiniones sobre estos ítems abre la cuestión sobre el reconocimiento o no de la diversidad y la necesidad de dar respuestas a la misma que redunden en una igualdad de oportunidades $\mathrm{y}$, consecuentemente, en una mayor inclusión social del alumnado con discapacidad.

Por otro lado, el 96,4\% de los estudiantes encuestados creen necesario fomentar relaciones favorables hacia sus compañeros con discapacidad (número 20) como demuestra la media de 3,63 y una dispersión de o,6I. Fomento que la propia UPNa debería realizar también poniendo medios para facilitar la participación (número 27) y, de esta forma, la visibilización y sensibilización del alumnado con discapacidad (media 3,67). Este dato se concreta en la pregunta 30 , donde la mayoría de encuestados $(87,7 \%)$ coinciden en reconocer la necesidad de formación/sensibilización sobre este tema. Es decir, se reconoce la falta de sensibilidad sobre la inclusión social del alumnado con discapacidad en la comunidad universitaria (números 20, 30 y 45). Es más, no se da un amplio acuerdo entre quienes opinan que la inclusión socioeducativa está (54,3\%) y no está $(45,7 \%)$ asumida en la Universidad (número 45). 
Tabla 4. Media y desviación típica del factor teórico Ideas

\begin{tabular}{|c|c|c|c|c|c|c|c|}
\hline \multirow[b]{2}{*}{ Ideas } & \multirow[b]{2}{*}{$\mathbf{N}$} & \multicolumn{4}{|c|}{ Porcentajes $^{7}$} & \multirow[b]{2}{*}{$\bar{x}$} & \multirow[b]{2}{*}{$\sigma$} \\
\hline & & 1 & 2 & 3 & 4 & & \\
\hline \multicolumn{6}{|l|}{ General } & 3,11 & 0,71 \\
\hline 12. Se debe facilitar el acceso del alumnado con discapacidad a la Universidad & 139 & 2,9 & 0 & 13,7 & 83,5 & 3,78 & 0,59 \\
\hline 14. A los/as estudiantes con discapacidad no les cuesta más terminar una carrera* & 138 & 4,3 & 31,9 & 47,8 & 15,9 & 2,75 & 0,77 \\
\hline 17. La existencia en las aulas de estudiantes con discapacidad no dificulta el aprendizaje* & 139 & 12,9 & 14,4 & 21,6 & 51,1 & 3,11 & 1,08 \\
\hline 18. Los objetivos y contenidos deben ser los mismos para todos los/as estudiantes & 139 & 2,2 & 15,1 & 46 & 36,7 & 3,17 & 0,76 \\
\hline $\begin{array}{l}\text { 20. Se deben fomentar actitudes favorables hacia la integración de estudiantes con } \\
\text { discapacidad }\end{array}$ & 139 & 1,4 & 2,2 & 28,8 & 67,6 & 3,63 & 0,61 \\
\hline $\begin{array}{l}\text { 23. Debe existir una unidad central que coordine y asesore a estudiantes con discapacidad, al } \\
\text { profesorado implicado en su formación y al personal de administración y servicios }\end{array}$ & 139 & 0 & 2,9 & 45,3 & 51,8 & 3,49 & 0,56 \\
\hline $\begin{array}{l}\text { 25. Debe informarse a los/as estudiantes de la existencia en sus aulas de compañeros/as con } \\
\text { discapacidad matriculados }\end{array}$ & 138 & 20,3 & 34,8 & 35,5 & 9,4 & 2,34 & 0,91 \\
\hline 26. Debe existir en la Universidad profesorado especializado para estos/as estudiantes & 138 & 2,9 & 20,3 & 54,3 & 22,5 & 2,96 & 0,74 \\
\hline $\begin{array}{l}\text { 27. La Universidad debe poner los medios para que los/as estudiantes con discapacidad } \\
\text { participen en la vida universitaria como el resto de compañeros/as }\end{array}$ & 139 & 0 & 2,2 & 28,8 & 69,1 & 3,67 & 0,52 \\
\hline $\begin{array}{l}\text { 28. En la Universidad no deben existir grupos específicos para los/as estudiantes con } \\
\text { discapacidad* }^{*}\end{array}$ & 138 & 5,1 & 26,1 & 51,4 & 17,4 & 2,81 & 0,78 \\
\hline $\begin{array}{l}\text { 29. Es necesario que la Universidad firme convenios de colaboración con asociaciones e } \\
\text { instituciones públicas y/o privadas para mejorar la atención al alumnado con discapacidad }\end{array}$ & 139 & 1,4 & 5 & 58,3 & 35,3 & 3,27 & 0,62 \\
\hline $\begin{array}{l}\text { 30. Es necesaria la formación/sensibilización de los/as estudiantes para facilitar la estancia en la } \\
\text { Universidad de las personas con discapacidad }\end{array}$ & 139 & 2,2 & 10,1 & 57,5 & 30,2 & 3,16 & 0,68 \\
\hline $\begin{array}{l}\text { 31. La Universidad es el lugar más adecuado para la formación académica y profesional de los/ } \\
\text { as estudiantes con discapacidad* }\end{array}$ & 139 & 15,8 & 11,5 & 20,1 & 52,6 & 3,09 & 1,13 \\
\hline $\begin{array}{l}\text { 32. La presencia en las aulas de personas con discapacidad no supone problemas y } \\
\text { dificultades* }\end{array}$ & 139 & 11,5 & 17,3 & 32,4 & 38,8 & 2,99 & 1,01 \\
\hline $\begin{array}{l}\text { 33. Debe existir una normativa específica que regule la atención a los/as estudiantes con } \\
\text { discapacidad en la Universidad }\end{array}$ & 133 & 3,8 & 21,8 & 55,6 & 18,8 & 2,89 & 0,74 \\
\hline $\begin{array}{l}\text { 36. La Universidad dispone de los medios para solventar cualquier tipo de adaptación en el } \\
\text { acceso al currículum para estos estudiantes }\end{array}$ & 121 & 5,8 & 43,8 & 49,6 & 0,8 & 2,45 & 0,62 \\
\hline $\begin{array}{l}\text { 37. Con este alumnado se debe tener más flexibilidad a la hora de exigirles la adquisición de las } \\
\text { competencias propias de las titulaciones/carreras }\end{array}$ & 139 & 12,2 & 54 & 39,9 & 2,9 & 2,24 & 0,70 \\
\hline 38. La presencia en las aulas de estudiantes con discapacidades es beneficioso para todos/as & 137 & 0,7 & 9,5 & 54,7 & 35 & 3,24 & 0,65 \\
\hline $\begin{array}{l}\text { 39. Se deben incrementar los esfuerzos económicos para la atención a los/as estudiantes con } \\
\text { discapacidad }\end{array}$ & 137 & 2,2 & 11,7 & 63,5 & 22,6 & 3,07 & 0,66 \\
\hline $\begin{array}{l}\text { 40. La presencia en las aulas de estudiantes con discapacidad no produce un descenso del } \\
\text { nivel académico generalizado* }\end{array}$ & 139 & 13,7 & 13,9 & 22 & 50,4 & 3,10 & 1,09 \\
\hline $\begin{array}{l}\text { 41. Los/as estudiantes con discapacidad deben tener las mismas oportunidades y posibilidades } \\
\text { de promoción que los/as demás universitarios/as }\end{array}$ & 138 & 1,4 & 1,4 & 18,2 & 79 & 3,75 & 0,55 \\
\hline $\begin{array}{l}\text { 42. Las pruebas de acceso a la universidad deben contemplar los recursos y adaptaciones } \\
\text { necesarias para dar respuesta a las necesidades de los/as estudiantes con discapacidad }\end{array}$ & 136 & 0 & 4,4 & 47,1 & 48,5 & 3,44 & 0,58 \\
\hline $\begin{array}{l}\text { 43. La titulación alcanzada por el alumnado con discapacidad debe ser garante del conjunto de } \\
\text { competencias para su ejercicio profesional }\end{array}$ & 130 & 0 & 3,8 & 56,9 & 39,2 & 3,35 & 0,55 \\
\hline $\begin{array}{l}\text { 44. Los/as estudiantes, especialmente aquellos que presentan alguna situación de } \\
\text { discapacidad, deben conocer las competencias que se exigirán en cada titulación/carrera antes } \\
\text { de formalizar su matrícula }\end{array}$ & 136 & 0,7 & 7,4 & 61,8 & 30,1 & 3,21 & 0,60 \\
\hline
\end{tabular}

7. I. "Totalmente en desacuerdo", 2. "En desacuerdo", 3. "De acuerdo" y 4. "Totalmente de acuerdo". Porcentajes. 


\begin{tabular}{|c|c|c|c|c|c|c|c|}
\hline \multirow[b]{2}{*}{ Ideas } & \multirow[b]{2}{*}{$\mathbf{N}$} & \multicolumn{4}{|c|}{ Porcentajes $^{7}$} & \multirow[b]{2}{*}{$\bar{x}$} & \multirow[b]{2}{*}{$\sigma$} \\
\hline & & 1 & 2 & 3 & 4 & & \\
\hline \multicolumn{6}{|l|}{ General } & 3,11 & 0,71 \\
\hline 45. La inclusión de las personas con discapacidad está asumida por la comunidad universitaria & 127 & 3,9 & 41,8 & 48,8 & 5,5 & 2,56 & 0,66 \\
\hline $\begin{array}{l}\text { 48. Se deben incrementar los esfuerzos económicos para mejorar la atención educativa que } \\
\text { reciben las personas con discapacidad }\end{array}$ & 134 & 0,7 & 7,5 & 70,1 & 21,6 & 3,13 & 0,55 \\
\hline $\begin{array}{l}\text { 49. Es necesario que exista comunicación entre compañeros/as como apoyo y ayuda a } \\
\text { estudiantes con discapacidad }\end{array}$ & 138 & 1,4 & 0 & 55,8 & 42,8 & 3,40 & 0,57 \\
\hline
\end{tabular}

*Recodificado.

Fuente: elaboración propia.

Los resultados del factor teórico Actitudes (Tabla 5) refuerzan los datos obtenidos en el factor Ideas. Así, se muestra una alta receptividad a la hora de tener compañeros/ as con discapacidad en clase $(74,8 \%)$, de ahí que no les genere ansiedad $(72 \%)$ ni pena ni compasión ni formas de sobreprotección $(70,8 \%)$ compartir tareas con este colectivo. Si bien estos últimos datos muestran resultados positivos, es preciso hacer hincapié en el más del $25 \%$ de estudiantes que sí señalan padecer ansiedad o sentir pena de las personas con discapacidad dentro de las aulas. Ahora bien, se percibe predisposición para un cambio de actitud cuando un $84,2 \%$ de encuestados afirma tener preparación para relacionarse con estudiantes con discapacidad (media de 3,22) y un $94,2 \%$ estaría dispuesto a formarse más (media de 3,04 y desviación de o,69).

\section{Tabla 5. Media y desviación típica del factor teórico Actitudes $^{8}$}

\begin{tabular}{|c|c|c|c|c|c|c|c|}
\hline \multirow[b]{2}{*}{ Actitudes } & \multirow[b]{2}{*}{$\mathbf{N}$} & \multicolumn{4}{|c|}{ Porcentajes $^{8}$} & \multirow[b]{2}{*}{$\bar{x}$} & \multirow[b]{2}{*}{$\sigma$} \\
\hline & & 1 & 2 & 3 & 4 & & \\
\hline \multicolumn{6}{|l|}{ General } & 3,09 & 0,87 \\
\hline 13. Prefiero tener compañeros/as con discapacidad en clase* & 139 & 18,7 & 6,5 & 10,8 & 64 & 3,20 & 1,19 \\
\hline 15. No me produce ansiedad trabajar con compañeros/as con discapacidad* & 139 & 12,9 & 15,1 & 28,8 & 43,2 & 3,02 & 1,05 \\
\hline $\begin{array}{l}\text { 16. No tengo más dificultad para relacionarme con compañeros/as que presentan alguna } \\
\text { situación de discapacidad* }\end{array}$ & 139 & 11,5 & 24,5 & 37,4 & 26,6 & 2,79 & 0,97 \\
\hline $\begin{array}{l}\text { 19. No siento pena, compasión o lástima por el alumnado con discapacidad y tiendo a } \\
\text { ayudarles en exceso, sin valorar sus posibilidades* }\end{array}$ & 137 & 5,1 & 24,1 & 43,8 & 27 & 2,93 & 0,85 \\
\hline $\begin{array}{l}\text { 21. Se debe facilitar al alumnado con discapacidad el acceso a los contenidos y a la } \\
\text { evaluación según sus necesidades }\end{array}$ & 138 & 0 & 5,8 & 42 & 52,2 & 3,46 & 0,61 \\
\hline $\begin{array}{l}\text { 22. Estoy dispuesto/a a formarme para facilitar la estancia en la Universidad de los/as } \\
\text { estudiantes con discapacidad }\end{array}$ & 138 & 2,2 & 15,2 & 59,4 & 23,2 & 3,04 & 0,69 \\
\hline $\begin{array}{l}\text { 24. Me siento preparado/a para relacionarme con estudiantes con discapacidad en la } \\
\text { Universidad }\end{array}$ & 139 & 0,7 & 15,1 & 45,3 & 38,9 & 3,22 & 0,72 \\
\hline
\end{tabular}

*Recodificado.

Fuente: elaboración propia.

8. I. "Totalmente en desacuerdo", 2. "En desacuerdo", 3. "De acuerdo" y 4. "Totalmente de acuerdo". 


\subsection{Actitudes en la sociedad general}

La Actitud General se ha medido con cinco factores cuya media es de 4,8 en una escala del I al 6 (Tabla 6), lo que supone una actitud general positiva hacia las personas con discapacidad, aunque la dispersión (I,3 I) es mayor que en la segunda parte del cuestionario. El factor Implicación personal registra la media más alta $(5,3$ I $)$ con un grado de dispersión de I,23, en tanto que el factor Asunción de Roles presenta la media más baja y una dispersión mayor que el resto de factores, a excepción del reconocimiento/negación de derechos, lo que significa que hay diversidad de opiniones entre el alumnado encuestado.

Tabla 6. Media y desviación típica de las
Actitudes Generales hacia la discapacidad
\begin{tabular}{|l|c|c|}
\hline & $\bar{x}$ & $\sigma$ \\
\hline $\begin{array}{l}\text { Actitud General hacia la } \\
\text { discapacidad }\end{array}$ & $\mathbf{4 , 8 0}$ & $\mathbf{1 , 3 1}$ \\
\hline $\begin{array}{l}\text { Valoración de capacidades y } \\
\text { limitaciones }\end{array}$ & 4,96 & 1,20 \\
\hline $\begin{array}{l}\text { Reconocimiento/Negación de } \\
\text { derechos }\end{array}$ & 4,98 & 1,45 \\
\hline Implicación personal & 5,31 & 1,23 \\
\hline Calificación genérica & 4,63 & 1,19 \\
\hline Asunción de roles & 4,09 & 1,43 \\
\hline
\end{tabular}

Fuente: elaboración propia.

\subsection{Análisis de relaciones de los resultados del cuestionario}

La Tabla 7 recoge las relaciones significativas entre la variable independiente sexo y las preguntas que sobre ideas y actitudes conforman el cuestionario. Como se observa, las mujeres tienen una percepción más positiva que los hombres hacia las personas con discapacidad. La prueba T-Student confirma la existencia de dichas relaciones asociadas al sexo con una significatividad de $0,039(\mathrm{p}<0,05)$.

La relación de las ideas y actitudes del alumnado encuestado y la variable edad indica que personas de más de 3 I años son las que tienen una percepción más negativa sobre las personas con discapacidad (Tabla 8). El alumnado entre 2I y 25 años, predominante en la encuesta, se posiciona en un punto intermedio $(3,05)$, siendo el alumnado menor de 20 años el que se muestra más positivo en términos inclusivos. El resultado de la prueba ANOVA concluye que la edad del alumnado universitario afecta a la forma de percibir a las personas con discapacidad que estudian en la universidad $(\mathrm{p}=0,033)$.

Tabla 7. Resultados descriptivos y prueba T-Student, atendiendo a la variable independiente sexo

\begin{tabular}{|c|c|c|c|c|c|c|c|}
\hline & & & & & \multicolumn{3}{|c|}{ Prueba T-Student } \\
\hline & & $\mathbf{N}$ & $\bar{x}$ & $\sigma$ & $\mathbf{t}$ & gl & Sig.(bilateral) \\
\hline \multirow{3}{*}{$\begin{array}{l}\text { Ideas y } \\
\text { Actitudes }\end{array}$} & Hombre & 45 & 2,99 & 0,41 & \multirow{2}{*}{$-2,083$} & \multirow{2}{*}{137} & \multirow{2}{*}{,039 } \\
\hline & Mujer & 94 & 3,16 & 0,45 & & & \\
\hline & Total & 139 & 3,08 & 0,43 & & & \\
\hline
\end{tabular}

Fuente: elaboración propia. 


\begin{tabular}{|c|c|c|c|c|}
\hline & & $\mathbf{N}$ & $\bar{x}$ & $\sigma$ \\
\hline \multirow{5}{*}{ Ideas y actitudes } & Menos de 20 & 34 & 3,26 & 0,36 \\
\hline & De 21 a 25 & 88 & 3,05 & 0,47 \\
\hline & De 26 a 30 & 13 & 3,18 & 0,35 \\
\hline & Más de 31 & 4 & 2,73 & 0,46 \\
\hline & Total & 139 & 3,11 & 0,45 \\
\hline \multicolumn{2}{|c|}{ Prueba ANOVA } & & & \\
\hline $\mathbf{F}$ & Sig. & & & \\
\hline 3,004 & ,033 & & & \\
\hline
\end{tabular}

Fuente: elaboración propia.

Tabla 9. Resultados descriptivos y prueba T-Student atendiendo a la variable independiente contacto con personas con discapacidad

\begin{tabular}{|c|c|c|c|c|c|c|c|}
\hline & & & & & \multicolumn{3}{|c|}{ Prueba T-Student } \\
\hline & & $\mathbf{N}$ & $\bar{x}$ & $\sigma$ & $\mathbf{t}$ & gl & $\begin{array}{c}\text { Sig. } \\
\text { (bilateral) }\end{array}$ \\
\hline \multirow{3}{*}{$\begin{array}{l}\text { Ideas y } \\
\text { Actitudes }\end{array}$} & Sí & 113 & 3,18 & 0,39 & \multirow{2}{*}{3,696} & \multirow{2}{*}{31,19} & \multirow{2}{*}{,001 } \\
\hline & No & 26 & 2,77 & 0,54 & & & \\
\hline & Total & 139 & 2,98 & 0,47 & & & \\
\hline
\end{tabular}

Fuente: elaboración propia.

Tabla 10. Resultados descriptivos y prueba T-Student atendiendo a la variable independiente compartir/ haber compartido clases con estudiantes con discapacidad en la universidad

\begin{tabular}{|c|c|c|c|c|c|c|c|}
\hline & & & & & \multicolumn{3}{|c|}{ Prueba T-Student } \\
\hline & & $\mathbf{N}$ & $\bar{x}$ & $\sigma$ & $\mathbf{t}$ & gl & $\begin{array}{c}\text { Sig. } \\
\text { (bilateral) }\end{array}$ \\
\hline \multirow{3}{*}{ Ideas y Actitudes } & Sí & 60 & 3,29 & 0,32 & \multirow{2}{*}{4,708} & \multirow{2}{*}{133,309} & \multirow{2}{*}{, 000} \\
\hline & No & 78 & 2,97 & 0,48 & & & \\
\hline & Total & 138 & 3,13 & 0,4 & & & \\
\hline
\end{tabular}

Fuente: elaboración propia. 
En cuanto a mantener o haber mantenido contacto con personas con discapacidad, los resultados muestran una media mayor en el caso afirmativo (Tabla 9). Este hecho también se ha obtenido de la primera parte del cuestionario (Anexo I), donde un 8I,3\% de personas encuestadas afirma haber tenido contactos con otros estudiantes con discapacidad en diversos contextos.

Después de hacer el análisis a través de la prueba T-Student, los resultados muestran gran significatividad $(\mathrm{p}<\mathrm{O}, \mathrm{O} \mathrm{I})$. Por tanto, el contacto entre el alumnado general y las personas con discapacidad influye en la percepción de los primeros con respecto a los segundos. Estos resultados son similares al estudio llevado a cabo por Salinas (20I4).

Atendiendo a la variable relacionada con el alumnado que comparte o ha compartido aula con estudiantes con discapacidad según niveles educativos, un $46,3 \%$ señala tener o haber tenido contacto en el ámbito académico, siendo un $38,3 \%$ de estos quienes han tenido estudiantes con discapacidad en los estudios superiores a lo largo de todos los cursos o de forma puntual en alguna asignatura.

Únicamente el ámbito universitario presenta resultados de interés (Tabla Io). La media resultante es de 3,29 con una desviación típica de 0,32 , superior a las personas que no han tenido esta oportunidad $(2,97)$ y una mayor dispersión $(0,48)$. La prueba T-Student registra que únicamente en este caso existen diferencias significativas entre el alumnado encuestado $(\mathrm{p}<0, \infty \circ 0)$, es decir, hay una influencia clara en la percepción del alumnado con discapacidad según haya habido o no contacto con este colectivo.

\section{Discusión y conclusiones}

Conocer las ideas y actitudes del alumnado universitario sobre sus iguales con discapacidad resulta una tarea imprescindible para detectar el grado de efectividad de las acciones realizadas en etapas educativas previas en materia de inclusión social. De igual forma, facilita el conocimiento de la sensibilidad social sobre la discapacidad de quienes, en un plazo corto, van a ser profesionales en diferentes campos. La propia Convención insistía en 2006 en la importancia de la visibilización y sensibilización de la sociedad en su conjunto sobre la realidad, por otro lado compleja y diversa, de la discapacidad. Acciones y resultados que han de encaminarse a construir una sociedad más inclusiva y, con ello, cohesionada.

El presente estudio se ha centrado en el caso de la UPNa, una de las tres universidades presentes en la Comunidad Foral de Navarra. Por número total de estudiantes puede afirmarse que es de las de menor tamaño en España, pero desde sus orígenes ha mostrado interés por trabajar con y por la diversidad de sus estudiantes (origen, etnia, discapacidad o diversidad funcional, etc.). El número de estudiantes con discapacidad reconocida en su matrícula anual es reducido: entre 40 y 60 estudiantes, según los cursos académicos. Este dato no invalida la existencia de otros que, por motivos diferentes, optan por no indicar que tienen una discapacidad.

En general, los resultados obtenidos del alumnado universitario de las facultades de Ciencias Económicas, Humanas y Sociales, y Jurídicas muestran una actitud favorable hacia sus pares con discapacidad. Estos resultados coinciden con los obtenidos en otras investigaciones realizadas con anterioridad en universidades como las de Burgos, Almería o Alicante (Moreno et al., 2006; Sánchez, 2009; Martínez, 20Iо; Suriá et al., 20I I; Salinas, 20I4; González y Roses, 20I6). Como en dichos trabajos, se puede concluir que en la UPNa la existencia de actitudes generales positivas incide sobre la inclusión socioeducativa del colectivo con discapacidad (Novo-Corti y MuñozCantero, 20I 2; Muñoz-Cantero et al., 2013). A este respecto, Martínez (2010) va más allá y afirma que dichas actitudes hacia el colectivo con discapacidad pueden determinar su inclusión en la sociedad en gran medida, ya que hace referencia a los procesos de socialización, 
tanto individuales como grupales, en el contexto familiar, educativo, social y laboral. Por ello, la actitud positiva del alumnado encuestado de la UPNa es fundamental para desarrollar contextos inclusivos favorables, incluso a futuro, que supongan un cambio capaz de provocar la superación de prejuicios y estereotipos asentados.

De todas formas, aunque los resultados obtenidos son positivos en términos generales, un porcentaje nada desdeñable de más del $25 \%$ de los estudiantes encuestados confirman el mantenimiento de ideas y actitudes poco inclusivas. Este es el caso de los sentimientos de pena y sobreprotección, de la actitud exclusógena a la hora de compartir el aula o de la falta de reconocimiento hacia la diversidad. El mismo colectivo estudiantil reconoce el déficit formativo, de visibilización e información de la realidad de la discapacidad en el entorno universitario. No hay duda de que todas esas barreras sociales a la inclusión requieren respuestas desde la propia universidad, pero también desde las etapas preuniversitarias. Como se expresaba en la introducción, se han dado pasos importantes hacia la inclusión de las personas con discapacidad, pero no son suficientes.

También se han obtenido relaciones significativas en las cuatro variables independientes seleccionadas: sexo, edad, tener o haber tenido contacto previo y haber compartido aula con personas con discapacidad, sobre todo, en la universidad. Como en la actitud general, estos resultados están en línea con los alcanzados en los trabajos de Sánchez (2009) y Martínez (2010), hecho que hace pensar en la existencia de ciertos roles (cuidados o identidad grupal) y la influencia que se puede ejercer a lo largo de toda la trayectoria académica. Ahora bien, se han detectado algunas diferencias, como en la variable sexo. En el presente trabajo, las mujeres tienen una percepción más positiva hacia las personas con discapacidad que sus pares masculinos, no siendo así en la investigación de Sánchez (2009). Tomando la variable edad, quienes están cursando $\mathrm{I}^{\circ} \mathrm{O} 2^{\circ}$ de algún grado (menores de
20 años) muestran una actitud más inclusiva que el resto del alumnado. Aunque sea a modo de hipótesis, puede pensarse que este resultado sea un indicio de una sensibilización real en este tema en niveles educativos no universitarios. Si esto fuera así, nos encontraríamos ante un avance en la inclusión de las personas con discapacidad en el sistema educativo, a pesar de que el acceso a niveles medios y superiores de estas personas sea menor en comparación al resto de estudiantes (Díez et al., 20I I; Observatorio Estatal de la Discapacidad, 201 2; Moriña, 20I 5). De cualquier forma, es mucha la tarea que está todavía pendiente en materia de diversidad humana (García-Santesmases y Herrero, 20I 2; Cobos y Moreno, 20I4).

Hay evidencia suficiente de cómo la convivencia es determinante para mejorar las actitudes hacia la realidad de la discapacidad y, a su vez, supone un mayor grado de sensibilización (Guasch, 20I2; González y Roses, 2016). También la hay sobre actitudes favorables hacia la implicación personal, la colaboración y el apoyo a las personas con discapacidad, pero a la vez el desconocimiento respecto a los sentimientos de competencia personal que manifiesta el colectivo con discapacidad (Martínez, 2010).

Tales constataciones se han registrado también en el caso de la UPNa. En lo referente a la existencia o no de contactos con personas con discapacidad, el $80 \%$ afirma haberlos tenido tanto fuera como dentro del campus universitario. De este grupo, el $38 \%$ ha tenido contacto en la universidad. No ha sido posible establecer si dichos contactos o relaciones son de amistad o afinidad entre estudiantes. El espacio universitario, por sus propias características, lo que facilita es el contacto directo y la interacción dentro de unos marcos específicos. Pero compartir aulas no es sinónimo de mantener relaciones de amistad o afinidad también fuera de las mismas. Cabe la posibilidad de que únicamente compartan espacios, por lo que no es posible hablar de plena inclusión socioeducativa. Esta posibilidad se acrecienta a la luz de los resultados de Martínez (20I0) y Guasch (20I2), que apuntan que el desconocimiento 
de la realidad de la discapacidad es la causa de la falta de acercamiento o el no mantener relaciones de amistad entre el alumnado con y sin discapacidad, así como del mantenimiento de prejuicios y estereotipos. Es por ello vital la sensibilización y formación de toda la comunidad universitaria en este tema, con el objetivo de trabajar la diversidad en su máxima expresión, atendiendo a las capacidades, entendida como una oportunidad positiva hacia el enriquecimiento personal y profesional.

En conclusión, los resultados que se han obtenido muestran la existencia de actitudes positivas hacia el alumnado con discapacidad en la UPNa por parte de quienes cursan titulaciones con un fuerte contenido social. Asimismo, hay que reconocer la existencia de constantes o de patrones de actitudes e ideas en las distintas universidades de España. Es posible, por tanto, pensar en un futuro prometedor en cuanto a la inclusión socioeducativa. Todo apunta a que la formación y la concienciación del alumnado en materia de discapacidad a lo largo de toda la vida académica es la base para facilitar la igualdad de oportunidades, la no discriminación y la inclusión social plena de quienes pueden ser futuros compañeros de trabajo, de ocio, de formación. El reto de la inclusión sigue presente, en suma, tanto dentro como fuera del ámbito educativo universitario. 
Abellán, R. M. et al. (20I0): "Una aproximación a la educación inclusiva en España”. Revista de educación inclusiva, 3 (I): I49-I64.

Anaut, S. y Arza, J. (201 5): “La exclusión social en los hogares con algún miembro con discapacidad durante el período de crisis en España”. Revista Española de Discapacidad, 3 (I): 7-28.

Anaut, S. et al. (20I7): "La exclusión social, una problemática estructural entre las personas con discapacidad". Áreas. Revista Internacional de Ciencias Sociales, 36: I7I-I86.

Anaut, S. et al. (20IO): "El impacto de la crisis económica sobre los hogares con personas con discapacidad", en Laparra, M. y Pérez, B. (coords.): El primer impacto de la crisis en la cohesión social en España. Madrid: Fundación FOESSA-Cáritas Española.

Aragall, F. (2008): Diseño para Todos: un conjunto de instrumentos (en línea).

$<$ http://bit.ly/2jQDEil>, acceso I 5 de marzo de 2017 .

Cabeza, L. F. (2013): Estudio longitudinal sobre los estudiantes con discapacidad de la Universidad de Castilla - La Mancha (Tesis doctoral inédita). Cuenca: Universidad de Castilla-La Mancha-Departamento de Pedagogía.

Cano, I. (20I2): “Discapacidad, educación y universidad: especial referencia a la Universidad de Alcalá”. Anuario Facultad de Derecho, 5: I83-202.

Cobos, A. y Moreno, M. (2OI4): "Educación superior y discapacidad: análisis desde la experiencia de algunas universidades colombianas”. Revista Española de Discapacidad, 2 (2): 83-IоI.

Colectivo Ioé (2012): Discapacidades e inclusión social. Barcelona: Obra Social "La Caixa", Colección Estudios Sociales, 33.

Comisión Europea (2010): Estrategia Europea sobre Discapacidad 2010-2020: un compromiso renovado para una Europa sin barreras (COM (20I0) 636 final). Bruselas: Comisión Europea.

De la Fuente, Y. M. (coord.) (20I4): Formación Curricular en Diseño para Todas las Personas en Trabajo Social. Madrid: CRUE-Fundación ONCE.

De Lorenzo, R. y Palacios, A. (2016): “La convención internacional sobre los derechos de las personas con discapacidad: balance de una década de vigencia”, en Pérez, L. y De Lorenzo, $\mathrm{R}$. (dirs.): La convención internacional sobre los derechos de las personas con discapacidad. Madrid: CERMI-Fundación Derecho y Discapacidad.

Denhart, H. (2008): “Deconstructing Barriers: Perceptions of students labeled with learning disabilities in Higher Education". Journal of Learning Disabilities, 4I (6): 483-497.

Díez, E. et al. (20I I): Espacio Europeo de Educación Superior: estándares e indicadores de buenas prácticas para la atención a estudiantes universitarios con discapacidad. Salamanca: INICO.

Escudero, J. M. (20I2): "La educación inclusiva, una cuestión de derecho”. Educatio Siglo XXI, 30 (2): IO9-I 28.

España. Real Decreto Legislativo I/20I3, de 29 de noviembre por el que se aprueba el Texto Refundido de la Ley General de derechos de las personas con discapacidad y de su inclusión social, Boletín Oficial del Estado, 3 de diciembre de 2013, núm. 289, pp. 9563595673 .

España. Ley Orgánica 4/2007, de I 2 de abril, por la que se modifica la Ley Orgánica 6/200I, de 2 I de diciembre, de Universidades, Boletín Oficial del Estado, I3 de abril de 2007, núm. 89 , pp. I624I-I6260.

Ferreira, M. A. V. (2008a): “Modernidad, Individuo y Discapacidad: una infundamentación ética". Revista Intersticios. 
Revista Sociológica de Pensamiento Crítico, 2 (2): 3-I3.

Ferreira, M. A. V. (2008b): Discapacidad, individuo y normalidad: la "axiomática" de la marginación. Actas de las V Jornadas nacionales "Universidad y Discapacidad", Argentina.

Flores, N. y Jenaro, C. (2009): “Riesgos Laborales y engagement en trabajadores con discapacidad intelectual”, en Verdugo, M. A. et al. (coords.): Mejorando. Resultados personales para una vida de calidad. Salamanca: Amarú.

Fundación ONCE (20I4): Formación Curricular en Diseño para Todas las Personas (en línea). <http://bit.ly/2vlnmoV>, acceso 9 de agosto de 2017

Fundación Universia (2016): Guía de atención a la Discapacidad en la Universidad (en línea). $<$ http://bit.ly/2vlpiev>, acceso 9 de agosto de 2017.

García de Sola, M. (coord.) (2006): Libro Blanco del Diseño para todos en la universidad. Madrid: Fundación ONCE, IMSERSO.

García-Santesmases, A. y Herrero, C. (20I 2): Análisis de las causas que dificultan el acceso del alumnado con discapacidad a la universidad y a la formación profesional. Madrid: Real Patronato sobre Discapacidad.

Garzón, P. et al. (2016): "Inclusión educativa. Actitudes y estrategias del profesorado". Revista Española de Discapacidad, 4 (2): 2545 .

González, E. y Roses, S. (2016): “¡Barreras invisibles? Actitudes de los estudiantes universitarios ante sus compañeros con discapacidad". Revista Complutense de Educación, 27 (I): 219- 235.

Guasch, D. (coord.) (20I2): Guía de Responsabilidad Social Universitaria y Discapacidad: RSU-D ( $\mathrm{I}^{\mathrm{a}}$ ed.). Barcelona: Cátedra de Accesibilidad.

Huete, A. (2013): Pobreza y exclusión social de las mujeres con discapacidad en España. Madrid: Ediciones Cinca-CERMI.
Martín-Padilla, E. et al. (20I3): "Educación inclusiva y discapacidad en la Universidad". Revista Facultad de Medicina, 6I (2): I95-204.

Martínez, M. A. (2010): Los estudiantes con discapacidad en la Universidad de Burgos (Tesis doctoral inédita). Burgos: Universidad de Burgos.

Martínez, M. A. y Bilbao, M.C. (2OII): "Los docentes de la universidad de Burgos y su actitud hacia las personas con discapacidad". Siglo Cero: Revista Española sobre Discapacidad Intelectual, 42 (240): 50-78.

Moreno, F.J. et al. (2006): “Actitudes ante la discapacidad en el alumnado universitario matriculado en materias afines". Revista Iberoamericana de Educación, 40 (5): I-I2.

Moriña, A. (20I7): "Inclusive education in higher education: challenges and opportunities". European Journal of Special Needs Education, 32 (I): 3-I7.

Moriña, A. (20 I 5): “ ¿Contextos universitarios inclusivos? Un análisis desde la voz del alumnado con discapacidad". Cultura y Educación, 27 (3): 669-694.

Moriña, A. et al. (20I4): "Inclusive curricula in Spanish higher education? Students with disabilities speak out”. Disability \& Society, 29 (I): 44-57.

Muñoz-Cantero, J. M. et al. (20I3): "La inclusión de los estudiantes universitarios con discapacidad en las universidades presenciales: actitudes e intención de apoyo por parte de sus compañeros". Estudios sobre educación, 24 : IO3-I 24 .

Novo-Corti, I. y Muñoz-Cantero, J.M. (2OI2): "Los estudiantes universitarios ante la inclusión de sus compañeros con discapacidad: indicadores basados en la Teoría de la Acción Razonada para los estudios de Economía y Empresa en la Universidad de A Coruña (España)". Revista Española de Orientación y Pedagogía, 23 (2): I05-I 22.

Núñez, M. T. (20I7): "Estudiantes con discapacidad e inclusión educativa en la Universidad: Avances y retos para el futuro”. 
Revista Nacional e Internacional de Educación Inclusiva, Iо (I): I3-30.

Observatorio Estatal de la Discapacidad (2OI2):

Censo de alumnos universitarios con discapacidad. Avance de resultados. Actas del I Congreso Internacional Universidad y Discapacidad. Madrid: Fundación ONCE.

ONU. Convención de Naciones Unidas sobre los Derechos de las Personas con discapacidad de I3 de diciembre de 2006, Resolución publicada el 24 de enero de 2007. Ratificada por España por medio de Instrumento de ratificación, Boletín Oficial del Estado, 2I de abril de 2008, núm. 96, pp. 20648-20659.

Palacios, A. (2008): El modelo social de discapacidad: orígenes, caracterización y plasmación en la Convención Internacional sobre los Derechos de las Personas con Discapacidad ( $I^{a}$ ed.). Madrid: CERMI.

Powell, J. J. W. (20I3): “From Ableism to Accessibility in the Universal Design University". Review of Disability Studies: An International Journal, 8 (4):33-45.

Rodríguez-Martín, A. y Álvarez-Arregui, E. (20I4): "Estudiantes con discapacidad en la Universidad. Un estudio sobre su inclusión”. Revista Complutense de Educación, 25 (2): 457-479.

Salinas, M. (20I4): Actitudes de estudiantes sin discapacidad hacia la inclusión de estudiantes con discapacidad en la Educación Superior (Tesis doctoral inédita). Barcelona: Universidad Autónoma de Barcelona.
Sánchez, A. (20I I): "La Universidad de Almería ante la integración educativa y social de los estudiantes con discapacidad: ideas y actitudes del personal docente e investigador". Revista de Educación, 354: 575-603.

Sánchez, A. (coord.) (2009): Integración educativa $y$ social de los estudiantes con discapacidad en la Universidad de Almería. Almería: Universidad de Almería.

Sánchez, M. O. y Solar, J. I. (2016): "El impacto de la Convención internacional sobre los derechos de las personas con discapacidad en los territorios: el caso de Cantabria”, en Pérez, L. y de Lorenzo, R. (dirs.): La convención internacional sobre los derechos de las personas con discapacidad. Madrid: CERMI-Fundación Derecho y Discapacidad.

Suriá, R. et al. (20I I): "Prejuicios entre los estudiantes hacia las personas con discapacidad: reflexiones a partir del caso de la Universidad de Alicante". Alternativas: cuadernos de Trabajo Social, i 8: 75-90.

Universidad Pública de Navarra (20I6): Acción Social (en línea). https://goo.gl/4vnwov>, acceso 23 de agosto de 2017.

Valcarce, M. (20II): "De la escuela integradora a la escuela inclusiva". Innovación educativa, 2 I: II9-I3I.

Verdugo, M. A. et al. (I994): Actitudes hacia las personas con minusvalía. Madrid: Ministerio de Asuntos Sociales-Instituto Nacional de Servicios Sociales. 


\section{Anexo 1}

\begin{tabular}{|c|c|}
\hline 1. Sexo & $\begin{array}{l}\square \text { Hombre } \\
\square \text { Mujer }\end{array}$ \\
\hline 2. Edad & $\begin{array}{l}\square \text { Menos de } 20 \\
\square \text { De } 21 \text { a } 25 \\
\square \text { De } 26 \text { a } 30 \\
\square \text { Más de } 31\end{array}$ \\
\hline 2.1. Edad* & años \\
\hline 3. Centro de Estudios & \\
\hline 4. Titulación (estudios ya realizados) & \\
\hline 5. Curso actual & \\
\hline $\begin{array}{l}\text { 6. ¿Tienes algún tipo discapacidad? (con } \\
\text { certificado) }\end{array}$ & $\begin{array}{l}\square \text { 1. Sí } \\
\square \text { 2. No }\end{array}$ \\
\hline 7. En caso afirmativo, indica de qué tipo & $\begin{array}{l}\square \text { 1. Física } \\
\square \text { 2. Psíquica } \\
\square \text { 3. Auditiva } \\
\square \text { 4. Visual } \\
\square \text { 5. Otras } \\
\end{array}$ \\
\hline $\begin{array}{l}\text { 8. ¿Tienes o has tenido algún tipo } \\
\text { de contacto con personas con } \\
\text { discapacidad? }\end{array}$ & $\begin{array}{l}\square \text { 1. Sí } \\
\square \text { 2. No }\end{array}$ \\
\hline $\begin{array}{l}\text { 9. ¿Qué tipo de relación mantenías con } \\
\text { esa(s) persona(s)? }\end{array}$ & $\begin{array}{l}\square \text { 1. Amistad } \\
\square \text { 2. Académica } \\
\square \text { 3. Laboral } \\
\square \text { 4. Familiar } \\
\square \text { 5. Voluntariado } \\
\square \text { 6. Vecindario } \\
\square \text { 7. Otra }\end{array}$ \\
\hline $\begin{array}{l}\text { 10. En el caso de haber tenido en tus clases } \\
\text { compañeros/as con discapacidad, } \\
\text { señala en qué niveles (puedes señalar } \\
\text { más de una opción) }\end{array}$ & $\begin{array}{l}\square \text { 1. Primaria } \\
\square \text { 2. ESO } \\
\square \text { 3. Bachiller } \\
\square \text { 4. FP/Ciclos } \\
\square \text { 5. Universidad }\end{array}$ \\
\hline $\begin{array}{l}\text { 11. ¿Has recibido información en la UPNA } \\
\text { acerca de la presencia de compañeros/ } \\
\text { as con discapacidad? }\end{array}$ & $\begin{array}{l}\square \text { 1. Sí } \\
\square \text { 2. No }\end{array}$ \\
\hline
\end{tabular}

Fuente: elaboración propia. 


\section{Anexo 2}

Tabla 12. Preguntas sobre actitudes hacia las personas con discapacidad según factores ${ }^{9}$

\section{Valoración de capacidades y limitaciones}

1. Las personas con discapacidad con frecuencia son menos inteligentes que las demás personas

2. Un trabajo sencillo y repetitivo es el más apropiado para las personas con discapacidad

4. En el trabajo, una persona con discapacidad sólo es capaz de seguir instrucciones simples

7. Las personas con discapacidad funcionan en muchos aspectos como los niños

8. De las personas con discapacidad no puede esperarse demasiado

16. Muchas personas con discapacidad no pueden ser profesionales competentes*

21. En el trabajo, las personas con discapacidad no se entienden sin problemas con el resto de trabajadores*

29. La mayor parte de las personas con discapacidad son poco constantes

36. Las personas con discapacidad no son en general tan conscientes como las personas normales* Reconocimiento/Negación de derechos

6. Las personas con discapacidad deberían vivir con personas afectadas por el mismo problema

9. Las personas con discapacidad no deberían tener las mismas oportunidades de empleo que cualquier otra persona*

12. Las personas con discapacidad no deberían poder divertirse con las demás personas*

13. Las personas con discapacidad no tienen una personalidad tan equilibrada como cualquier otra persona*

14. Las personas con discapacidad no deberían poder casarse si lo desean*

15. Las personas con discapacidad deberían ser confinadas en instituciones públicas

17. A las personas con discapacidad se les debería impedir votar

22. No sería apropiado que las personas con discapacidad trabajaran y vivieran con personas normales*

23. A las personas con discapacidad se les debería prohibir pedir créditos o préstamos

27. Las personas con discapacidad no pueden hacer muchas cosas tan bien como cualquier otra persona*

35. Se debería prevenir que las personas con discapacidad tuvieran hijos

37. Deberían existir leyes que prohibieran casarse a las personas con discapacidad

Implicación personal

3. No permitiría que mi hijo aceptase la invitación a un cumpleaños que le hiciera un niño con discapacidad*

5. Me disgusta estar cerca de personas que parecen diferentes, o actúan de forma diferente

10. Las personas con discapacidad deberían mantenerse apartadas de la sociedad

11. Me importaría trabajar junto a personas con discapacidad*

25. No quiero trabajar con personas con discapacidad

26. En situaciones sociales, preferiría no encontrarme con personas con discapacidad

31. Si tuviera un familiar cercano con discapacidad, evitaría comentarlo con otras personas

Calificación genérica

18. Las personas con discapacidad a menudo están de mal humor

20. Generalmente las personas con discapacidad no son sociables*

24. Las personas con discapacidad generalmente son suspicaces

9. Preguntas pertenecientes al cuestionario "Escala de actitudes hacia las personas con discapacidad" (Verdugo et al., I994). Versión modificada por Martínez (2010). 
28. La mayoría de las personas con discapacidad están resentidas con las personas físicamente normales

34. La mayoría de las personas con discapacidad prefieren trabajar con otras personas que tengan su mismo problema

Asunción de roles

19. Las personas con discapacidad confían en sí mismas tanto como las personas normales

30. Las personas con discapacidad son capaces de llevar una vida social normal

32. La mayor parte de las personas con discapacidad están satisfechas de sí mismas

33. La mayoría de las personas con discapacidad sienten que son tan valiosas como cualquiera

*Recodificado.

Fuente: Martínez (2010). 